\title{
ATUAÇÃO DA ASSOCIAÇÃO BRASILEIRA DA INDÚSTRIA DO CAFÉ NA DINÂMICA DO SISTEMA AGROINDUSTRIAL DO CAFÉ
}

Action of the Brazilian coffee roasters association in the dynamics of the agricultural system of coffee

DOI: 10.48075/igepec.v25i1.25211

Geraldo Magela Jardim Barra 


\title{
ATUAÇÃO DA ASSOCIAÇÃO BRASILEIRA DA INDÚSTRIA DE CAFÉ NA DINÂMICA DO SISTEMA AGROINDUSTRIAL DO CAFÉ
}

\author{
Action of the Brazilian coffee roasters association in the dynamics of the \\ agricultural system of coffee
}

DOI: 10.48075/igepec.v25i1.25211

Geraldo Magela Jardim Barra

\begin{abstract}
Resumo: O objetivo deste estudo é entender o papel das associações na dinâmica do setor cafeeiro por meio da análise do papel da ABIC na coordenação do Sistema Agroindustrial do café como enfoque nos selos de qualidade. Foram realizadas pesquisa bibliográfica e análise de documentos históricos. Os resultados demonstram que a ABIC contribui para a coordenação do sistema agroindustrial do café ratificando estudos anteriores baseados na teoria institucional. Este estudo cria proposições em termos teóricos no campo de estudos de ações coletivas e propõe um esquema conceitual de análise para pesquisa em sistemas agroindustriais. O suporte da ABIC na coordenação do sistema agroindustrial por meio de seus selos de qualidade tem sido um fator importante para proporcionar força competitiva aos seus associados.
\end{abstract}

Palavras-chaves: Associação, café, torrefação, selos de qualidade.

Abstract: The aim of this study is to understand the role of associations in the dynamics of the coffee sector by analysing the role of ABIC in coordinating the Agro-industrial System of coffee as a focus on quality seals. Bibliographic research and analysis of historical documents were carried out. The results demonstrate that ABIC contributes to the coordination of the coffee agro-industrial system, ratifying previous studies based on institutional theory. This study creates propositions in theoretical terms in the field of collective action studies and proposes a conceptual scheme of analysis for research in agro-industrial systems. ABIC's support in coordinating the agro-industrial system through its quality seals has been an important factor in providing competitive strength to its associates.

Key words: Association, coffee, roasting, quality seals.

Resumen: El objetivo de este estudio es comprender el papel de las asociaciones en la dinámica del sector cafetero mediante el análisis del papel de ABIC en la coordinación del Sistema Agroindustrial del café como foco en sellos de calidad. Se realizaron investigaciones bibliográficas y análisis de documentos históricos. Los resultados demuestran que ABIC contribuye a la coordinación del sistema de café agroindustrial, ratificando estudios previos basados en la teoría institucional. Este estudio crea proposiciones en términos teóricos en el campo de los estudios de acción colectiva y propone un esquema de análisis conceptual para la investigación en sistemas agroindustriales. El apoyo de ABIC en la coordinación del sistema agroindustrial a través de sus sellos de calidad ha sido un factor importante para proporcionar fortaleza competitiva a sus miembros.

Palabras clave: associación, café, tostado, sellos de calidad. 
Informe GEPEC, ISSN: 1679-415X, Toledo, v. 25, n.1, p.10-26, jan./jun. 2021. 


\section{INTRODUÇÃO}

As associações assumiram um papel de maior destaque na agenda de pesquisas no Brasil pelas condições resultantes da democratização e, também, da desregulamentação econômica ocorrida a partir do final da década de 1980. Desde então, as associações passaram contribuir para a coordenação e para o aumento da competitividade dos sistemas produtivos e, em particular dos sistemas agroindustriais (MACHADO FILHO; MIZUMOTO; ZYLBERSZTAJN, 2006).

A discussão sobre as associações na coordenação dos sistemas agroindustriais é fundamental para se compreender a dinâmica do mercado cafeeiro, podendo evitar crises de segurança alimentar. Os sistemas agroindustriais precisam estar coordenados, seja pelo Estado e ou por agentes do mercado.

Entende-se que a coordenação pode ser realizada por ações coletivas de associações pois estas organizações têm a capacidade de atuar como um agente de coordenação, por ter a capacidade de preencher estrategicamente um espaço que era ocupado pelo Estado no período de regulamentação.

A partir da desregulamentação do setor cafeeiro na década de 1990, as associações expandiram sua atuação e passaram a exercer um papel importante para a coordenação dos sistemas agroindustriais, bem como para a competitividade de todo o setor. Elas se fortaleceram em virtude do papel que estão realizando na defesa dos interesses de seus membros e nas ações de coordenação.

As associações podem ser entendidas como ações coletivas que objetivam contribuir de forma positiva para o desempenho dos seus membros, por meio do provimento de bens coletivos e incentivos seletivos. A eficiência das ações de uma associação, em relação aos seus associados, é definida como a capacidade de gerar retorno maior do que o custo de ser membro, provendo resultados positivos quanto a bens coletivos e incentivos seletivos (NASSAR, 2001).

Com a desregulamentação, houve uma mudança profunda nas regras do jogo, criando um cenário competitivo, com remodelação do papel do Estado, das associações e das firmas. A coordenação que era exercida pelo Estado passou a ser realizada por outros agentes, como as associações, que passaram a atuar não só como agente de Interface, mas como agente de confiança e agente de coordenação.

No Brasil, a Associação Brasileira da Indústria de Café (ABIC) tem exercido um papel na evolução da qualidade dos cafés torrados e moídos. A ABIC por meio dos seus selos passou a representar na percepção dos consumidores brasileiros os cafés considerados de qualidade. Neste trabalho, a ABIC foi escolhida por ser reconhecida em âmbito nacional e internacional no mercado de café e por ter influenciado outras associações a adotar práticas similares de selos de qualidade.

As marcas dos cafés dos associados da ABIC são certificadas por quatro tipos de selos da associação: Programa de Qualidade do Café (754). Programa Cafés Sustentáveis do Brasil (24), Programa Cafés em Cápsulas (24), Selo de Pureza (1176). Além disso, há nos selos a classificação por segmentação: tradicional, extraforte, superior e gourmet.

Em 2019, a ABIC assinou um acordo de filiação com a Associação Brasileira de Café Solúvel (ABICS) com intuito de criar trabalhos e negócios conjuntos. Neste mesmo ano, a ABIC assinou uma cooperação técnica com a Federação dos Cafeicultores do Cerrado Mineiro, em uma conjugação de esforços baseados nos programas de certificação buscando uma harmonização dos programas com objetivo de criar uma cadeia de custódia (ABIC, 2020). 
A partir desta discussão, assume-se que é importante discutir o papel das associações no processo de coordenação de sistemas agroindustriais, apresentando o seguinte problema de pesquisa: qual é o papel dos selos de qualidade da ABIC no suporte a comercialização de cafés torrados e moídos? Para discutir o papel dos selos de qualidade da ABIC foi escolhido os quatro tipos de selos de qualidade desta associação, a saber: Selo de Pureza, Programa de Qualidade do Café, Programa Cafés Sustentáveis do Brasil, Programa Cafés em Cápsulas.

O objetivo deste estudo é entender o papel das associações na dinâmica do setor cafeeiro por meio da análise do papel da ABIC na coordenação do Sistema Agroindustrial do café como enfoque nos selos de qualidade. Para tanto, foi empregado o caminho teórico de North (1993) de se ver as instituições como "regras do jogo" e as organizações como "jogadores".

Este estudo cria proposições em termos teóricos no campo de estudos de ações coletivas enfocando o papel de Agente de Coordenação das associações de interesse privado. Para tanto, propõe-se um esquema conceitual de análise para pesquisa em sistemas agroindustriais.

Após esta introdução, é apresentado na seção seguinte o suporte teórico abordando as ações coletivas sob a ótica da teoria institucional e o papel das associações como agente de coordenação. Ainda nesta seção, é propõe-se um esquema conceitual de análise. Posteriormente, apresenta-se o percurso metodológico. $\mathrm{Na}$ seção resultados, apresenta-se os quatro selos de qualidade da ABIC. Em seguida, é realizada a discussão sobre o papel destes selos no mercado de café. No final, são apresentadas as considerações finais.

\section{REVISÃO DE LITERATURA 2.1 AÇÕES COLETIVAS SOB A ÓTICA DA TEORIA INSTITUCIONAL}

Williamson (2000) propõe um esquema conceitual e analítico composto por quatro níveis para o estudo das organizações econômicas, sendo possível aplicar aos estudos dos Sistemas Agroindustriais. Baseado nos trabalhos de Grannoveter, o primeiro nível é composto por instituições informais, costumes e tradições, cujo objeto de análise concentra-se sobre o conceito de embeddedness. O segundo nível é composto pelo ambiente institucional, no qual se encontram as regras formais do jogo, como a política, o judiciário, a burocracia). Nesse nível de análise, estão posicionadas as instituições formais, as quais são tratadas como sendo as regras do jogo por North (1993). O terceiro nível analítico é composto pela governança, na qual as características das transações são analisadas. Nesse nível de análise, concentra-se a estrutura de governança dos estudos desenvolvidos por Williamson (1985).

A nova sociologia econômica (NSE) apresenta-se como uma teoria apropriada para análise dos sistemas agroindustriais. Esta teoria é identificada com Granovetter (1985), por meio do conceito de embeddedness, quando se demonstra que as transações realizadas entre os agentes econômicos precisam ser compreendidas dentro das redes sociais nas quais foram estabelecidas, pois relações sociais interferem na construção de confiança (BARRA; LADEIRA, 2016).

O quadro 1 apresenta a aplicação das teorias institucionais para o estudo dos Sistemas Agroindustriais (SAG's). Os três níveis de análise foram selecionados em função do objetivo precípuo deste trabalho de pesquisa. 
Quadro 1 - Aplicação das Teorias Institucionais para Estudo de SAG's

\begin{tabular}{|c|c|c|l|}
\hline $\begin{array}{c}\text { Teoria } \\
\text { Nível }\end{array}$ & Composição & $\begin{array}{c}\text { Objeto de } \\
\text { análise }\end{array}$ & \multicolumn{1}{c|}{$\begin{array}{c}\text { Aplicação para as Pesquisas em Sistemas } \\
\text { Agroindustriais }\end{array}$} \\
\hline $\begin{array}{c}\text { NSE } \\
1^{\circ} .\end{array}$ & $\begin{array}{c}\text { Costumes, } \\
\text { Tradições, }\end{array}$ & Embeddedness & $\begin{array}{l}\text { Analisar o processo de funcionamento do SAG a } \\
\text { partir de uma abordagem das redes sociais. }\end{array}$ \\
\hline $\begin{array}{c}\text { NEI } \\
2^{0} .\end{array}$ & $\begin{array}{c}\text { Política, } \\
\text { Judiciário, } \\
\text { Burocracia }\end{array}$ & $\begin{array}{c}\text { Ambiente } \\
\text { Institucional }\end{array}$ & $\begin{array}{l}\text { Analisar o SAG considerando que o ambiente } \\
\text { institucional é relevante para o desenho das } \\
\text { organizações e suas estratégias. }\end{array}$ \\
\hline $\begin{array}{c}\text { ECT } \\
3^{\mathrm{o}} .\end{array}$ & Governança & $\begin{array}{c}\text { Estrutura de } \\
\text { Governança }\end{array}$ & $\begin{array}{l}\text { Analisar o SAG com possibilidades de aplicação em } \\
\text { sua coordenação. }\end{array}$ \\
\hline
\end{tabular}

Fonte: Baseado em Barra e Ladeira (2016).

Tradicionalmente, as associações vêm sendo tratadas nos estudos econômicos como rent-seeking. Não obstante, diversas pesquisas em países em desenvolvimento revelam uma ampla gama de funções e atividades empreendidas por estas organizações. Essas funções de suporte abordam questões cruciais de desenvolvimento econômico enfatizadas na Nova Economia Institucional, tais como: fortalecimento dos direitos de propriedade, redução dos custos da informação, e facilitação da coordenação vertical e horizontal (DONER; SCHNEIDER, 2000).

No Brasil, há um campo de estudos em consolidação que tratam as associações como agentes de coordenação (FARINA; AVEZEVO; SAES,1997; NASSAR, 2001, MACHADO FILHO; MIZUMOTO; ZYLBERSZTAJN, 2006; BARRA; OLIVEIRA; MACHADO, 2007; BARRA; LADEIRA, 2016).

Nessa linha de raciocínio, propõe-se a analogia com o futebol para delinear a dinâmica do ambiente institucional em sistemas agroindustriais, onde as instituições são tratadas como as "regras do jogo" e as organizações como "jogadores" North (1993). Propõe-se, neste trabalho, expandir a perspectiva de North (1993) propondo visualizar o Estado como o "juiz" com o papel de agente regulador e as associações como "treinadores" com o papel de agente coordenador.

Com a desregulamentação dos setores agrícolas, foi percebido que as falhas de mercado e as falhas de governo podem impulsionar o papel das associações, pois exercem o papel de agentes de coordenação e, além disso, tem a capacidade de prover bens coletivos, que estão sujeitos ao comportamento "carona”. Há vantagens ao serem providos por associações, conquanto os bens coletivos possam ser providos pelo Estado. Não obstante, como as associações estão sujeitos ao comportamento "carona", há o grande risco de perder associados (FARINA; AZEVEDO; SAES, 1997).

Olson (1999) contribuiu para as pesquisas sobre o papel das associações, ao estabelecer a proposição de que os grupos de interesses são provedores de benefícios coletivos e que a existência deles é dificultada pelo comportamento free rider (carona). O conceito de benefício coletivo como fator estimulador para a formação dos grupos, demonstra que os indivíduos sempre incentivados pelo próprio interesse, deveriam agrupar-se para prover os benefícios coletivos, pois nenhum agente estará disposto a arcar com seu custo de forma independente. Portanto, o conceito free rider está implícito na sua teoria sobre ação coletiva (NASSAR, 2001).

A pesquisa sobre o papel das instituições no crescimento econômico no mundo tem aumentado significativamente, onde as associações representam uma proporção dessas pesquisas. De fato, a pesquisa sobre o papel das instituições no crescimento econômico começou a destacar as ações coletivas das associações. A literatura sobre governança econômica em países industrializados demonstrou as maneiras pelas quais vários tipos de redes ajudaram a desenvolver vantagens institucionais, incluindo as associações. A compreensão das condições em que as associações afetam o crescimento no mundo em desenvolvimento permanece ainda não sistemática. Em parte, isso é o 
resultado da relativa negligência acadêmica com relação a estas organizações, pelo menos no contexto dos países em desenvolvimento. A maioria dos teóricos da Nova Economia Institucional dedicaram pouca atenção sistemática sobre as associações. Entretanto, estudos mostraram maneiras pelas quais associações em uma ampla variedade de contextos melhoraram o desempenho econômico em países em desenvolvimento (DONER \& SCHNEIDER, 2000).

Ao se inserir a discussão do papel das associações sob o prisma da Nova Economia Institucional, criam-se oportunidades de compreenderem-se as limitações e as dificuldades existentes nos mercados agroalimentares, bem como as possibilidades de atuação das associações. Logo, é necessário contextualizar as associações no ambiente institucional para se entender o papel desenvolvido por essas organizações no suporte a negócios de seus membros (BARRA; OLIVEIRA; MACHADO, 2007).

As associações contêm elementos que podem possibilitar a coordenação das atividades econômicas, podendo se constituir em instituições funcionais à gestão pública. O apoio dos agentes privados na regulamentação gera condições que facilitam os investimentos e a produção de bens públicos. As ações coletivas de defesa de interesses particulares podem se compatibilizar com os objetivos de interesse geral. As associações como possuidoras de informações podem ser úteis à política pública e ao planejamento setorial A associação compõe uma base diferente de ordem institucional com sua própria lógica, que não é explicada pela lógica das bases institucionais da sociedade (comunidade, mercado e estado). Ela consistiria em uma resposta das sociedades em relação a uma disfunção e conflito que não pode ser solucionada pelas outras três. Embora contribua para a ordem social, esta nova base não deixa de gerar relações que possam ser disfuncionais para os outros tipos de coordenação (SAES, 1995).

\subsection{O PAPEL COORDENADOR DAS ASSOCIAÇÕES}

Tradicionalmente, as associações vêm sendo tratadas nos estudos econômicos como rent-seeking. Não obstante, diversas pesquisas em países em desenvolvimento revelam uma ampla gama de funções e atividades empreendidas por estas organizações. Essas funções de suporte abordam questões cruciais de desenvolvimento econômico enfatizadas na Nova Economia Institucional, tais como: fortalecimento dos direitos de propriedade, redução dos custos da informação, e facilitação da coordenação vertical e horizontal (DONER; SCHNEIDER, 2000).

No Brasil, há um campo de estudos em consolidação que tratam as associações como agentes de coordenação (FARINA; AVEZEVO; SAES,1997; NASSAR, 2001, MACHADO FILHO; MIZUMOTO; ZYLBERSZTAJN, 2006; BARRA; OLIVEIRA; MACHADO, 2007; BARRA; LADEIRA, 2016).

Nessa linha de raciocínio, propõe-se a analogia com o futebol para delinear a dinâmica do ambiente institucional em sistemas agroindustriais, onde as instituições são tratadas como as "regras do jogo" e as organizações como "jogadores” North (1993). Propõe-se, neste trabalho, expandir a perspectiva de North (1993) propondo visualizar o Estado como o "juiz" com o papel de agente regulador e as associações como "treinadores" com o papel de agente coordenador.

Com a desregulamentação dos setores agrícolas, foi percebido que as falhas de mercado e as falhas de governo podem impulsionar o papel das associações, pois exercem o papel de agentes de coordenação e, além disso, tem a capacidade de prover bens coletivos, que estão sujeitos ao comportamento "carona”. Há vantagens ao serem providos por associações, conquanto os bens coletivos possam ser providos pelo 
Estado. Não obstante, como as associações estão sujeitos ao comportamento "carona", há o grande risco de perder associados (FARINA; AZEVEDO; SAES, 1997).

Olson (1999) contribuiu para as pesquisas sobre o papel das associações, ao estabelecer a proposição de que os grupos de interesses são provedores de benefícios coletivos e que a existência deles é dificultada pelo comportamento free rider (carona). O conceito de benefício coletivo como fator estimulador para a formação dos grupos, demonstra que os indivíduos sempre incentivados pelo próprio interesse, deveriam agrupar-se para prover os benefícios coletivos, pois nenhum agente estará disposto a arcar com seu custo de forma independente. Portanto, o conceito free rider está implícito na sua teoria sobre ação coletiva (NASSAR, 2001).

A pesquisa sobre o papel das instituições no crescimento econômico no mundo tem aumentado significativamente, onde as associações representam uma proporção dessas pesquisas. De fato, a pesquisa sobre o papel das instituições no crescimento econômico começou a destacar as ações coletivas das associações. A literatura sobre governança econômica em países industrializados demonstrou as maneiras pelas quais vários tipos de redes ajudaram a desenvolver vantagens institucionais, incluindo as associações. A compreensão das condições em que as associações afetam o crescimento no mundo em desenvolvimento permanece ainda não sistemática. Em parte, isso é o resultado da relativa negligência acadêmica com relação a estas organizações, pelo menos no contexto dos países em desenvolvimento. A maioria dos teóricos da Nova Economia Institucional dedicaram pouca atenção sistemática sobre as associações. Entretanto, estudos mostraram maneiras pelas quais associações em uma ampla variedade de contextos melhoraram o desempenho econômico em países em desenvolvimento (DONER \& SCHNEIDER, 2000).

Ao se inserir a discussão do papel das associações sob o prisma da Nova Economia Institucional, criam-se oportunidades de compreenderem-se as limitações e as dificuldades existentes nos mercados agroalimentares, bem como as possibilidades de atuação das associações. Logo, é necessário contextualizar as associações no ambiente institucional para se entender o papel desenvolvido por essas organizações no suporte a negócios de seus membros (BARRA; OLIVEIRA; MACHADO, 2007).

As associações contêm elementos que podem possibilitar a coordenação das atividades econômicas, podendo se constituir em instituições funcionais à gestão pública. O apoio dos agentes privados na regulamentação gera condições que facilitam os investimentos e a produção de bens públicos. As ações coletivas de defesa de interesses particulares podem se compatibilizar com os objetivos de interesse geral. As associações como possuidoras de informações podem ser úteis à política pública e ao planejamento setorial A associação compõe uma base diferente de ordem institucional com sua própria lógica, que não é explicada pela lógica das bases institucionais da sociedade (comunidade, mercado e estado). Ela consistiria em uma resposta das sociedades em relação a uma disfunção e conflito que não pode ser solucionada pelas outras três. Embora contribua para a ordem social, esta nova base não deixa de gerar relações que possam ser disfuncionais para os outros tipos de coordenação (SAES, 1995). 


\section{3 - ESQUEMA CONCEITUAL ANALÍTICO}

A combinação da NSE, NEI e ECT, neste trabalho, criou um arcabouço teórico apropriado para o estudo do papel das associações em sistemas agroindustriais. A NSE permite a compreensão do processo de funcionamento do sistema agroindustrial a partir de uma abordagem das redes sociais enfocando as instituições informais. Por sua vez, a NEI possibilita analisar este sistema produtivo por meio das instituições formais, considerando que o ambiente institucional é um fator relevante para o desenho das organizações e suas estratégias. A ECT permite analisar o sistema agroindustrial com possibilidades de aplicação em sua coordenação.

O esquema analítico proposto aqui sintetiza a representação do percurso teórico desenvolvido (Figura 1).

Figura 1 - Esquema Conceitual Analítico

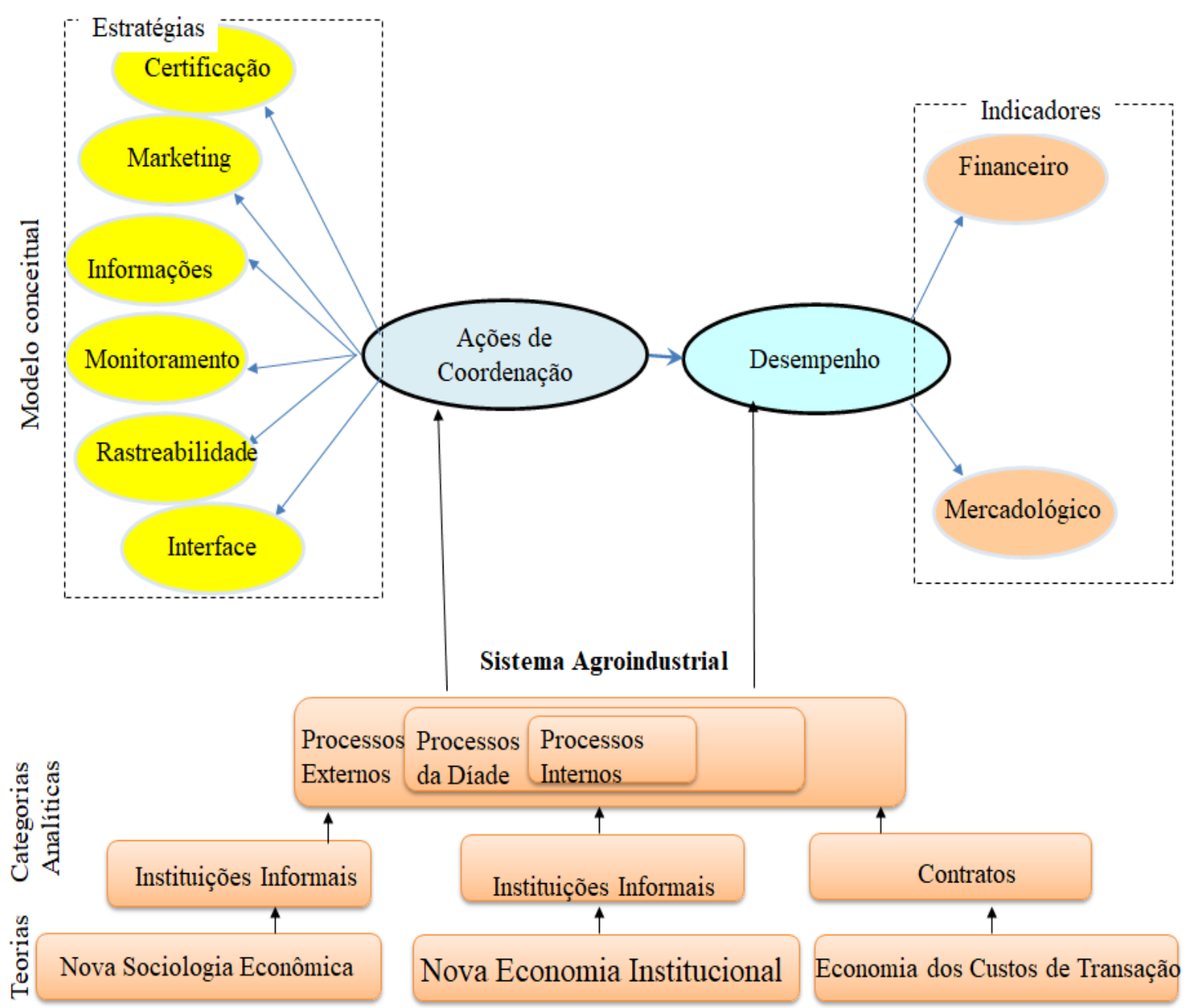

Fonte: elaborado pelo autor.

A associação é uma rede composta por firmas que tem a capacidade de coordenar os sistemas agroindustriais, sendo limitadas pelas instituições formais. Esta conjugação teórica é adequada para a compreensão das associações no papel de coordenação dos sistemas agroindustriais, uma vez que sua abrangência de pesquisa 
abarca as transações entre os agentes econômicos, envolvendo os processos internos da firma, da díade como também os processos externos.

As associações desenvolvem códigos de conduta para melhorar processos de seus membros por meio de certificações. Por meio do monitoramento das ações dos seus membros podem eliminar de seu quadro os associados que não cumprem as exigências mínimas contidas nestes códigos. Ações coercitivas desse tipo são mecanismos de geração de reputação. As Associações atuam no fornecimento de selos de qualidade dos produtos dos seus associados, que são facilitadores da negociação e contribuem para a redução dos custos de transação e para ações de marketing. As associações podem agir na coordenação de organizações tanto em nível horizontal quanto vertical, colaborando, assim, para a integração das cadeias produtivas (BARRA et al., 2007).

Ao participar de associações, as firmas têm a possibilidade de obter força competitiva por meio de estratégias coletivas, como: certificação envolvendo selos de qualidade, atividades de marketing, compartilhamento de informações, monitoramento dos agentes, rastreabilidade dos produtos e interface com agentes públicos e privados.

Estas estratégias têm a capacidade de contribuir de forma positiva para o desempenho dos associados com relação a desempenho financeiro e mercadológico. $\mathrm{O}$ Quadro 2 complementa a Figura 1, pormenorizando as ações das associações e conectando-as aos novos papéis desempenhados após a desregulamentação.

Quadro 2 - Categorias Analíticas

\begin{tabular}{|c|c|c|c|c|c|c|c|}
\hline Estratégias & $\begin{array}{l}10 \\
2 \\
= \\
\tilde{0} \\
\tilde{\omega} \\
\tilde{n}\end{array}$ & 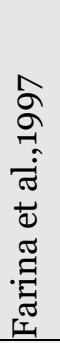 & 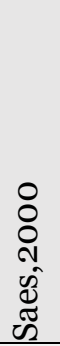 & 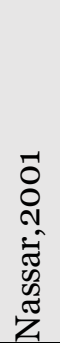 & 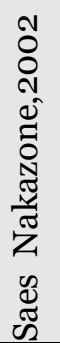 & 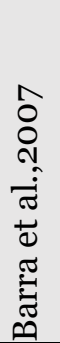 & 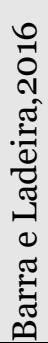 \\
\hline \multicolumn{8}{|l|}{ Agente de Coordenação } \\
\hline 1. Certificação de seus associados & & & & & & $\mathbf{X}$ & $\mathbf{X}$ \\
\hline 2. Controle de selos de qualidade & & & & & & $\mathbf{X}$ & \\
\hline 3. Monitoramento das ações de seus membros & & & & & & $\mathbf{X}$ & \\
\hline 4. Desenvolver códigos de conduta & & & & & & $\mathbf{X}$ & \\
\hline 5. Implantar Programas de Qualidade & & & & & & $\mathbf{X}$ & \\
\hline 6. Rastreabilidade & & & & & & & $\mathbf{X}$ \\
\hline 7. Resolução de conflitos entre agentes & & & $\mathbf{X}$ & & & & \\
\hline 8. Geração de ganhos de escala & & & $\mathbf{X}$ & & & & \\
\hline 9. Prover bens coletivos & & $\mathbf{X}$ & $\mathbf{X}$ & $\mathbf{X}$ & & & \\
\hline 10. Espaço para a aprendizagem coletiva & & & & & & $\mathbf{X}$ & \\
\hline \multicolumn{8}{|l|}{ Agente de Confiança } \\
\hline 11. Redução de custos de transação & & & $\mathbf{X}$ & & & & \\
\hline 12. Desenvolver estabilidade institucional & & & & & & & $\mathbf{X}$ \\
\hline 13. Marketing conjunto & & & & & $\mathbf{X}$ & $\mathbf{X}$ & \\
\hline 14. Provimento de benefícios coletivos & & & $\mathbf{X}$ & & & & \\
\hline \multicolumn{8}{|l|}{ Agente de Interface } \\
\hline 15. Intermediários entre agentes públicos e privados & & $\mathbf{X}$ & & & & & \\
\hline 16. Influência na modificação das "regras do jogo" & & & $\mathbf{X}$ & & & & \\
\hline 17. Defesa do interesse de seus membros & $\mathbf{X}$ & & & & & & \\
\hline 18. Provisão de informações setoriais & $\mathbf{X}$ & & & & $\mathbf{X}$ & & \\
\hline 19. Participação na implantação de políticas setoriais & & $\mathbf{X}$ & & & $\mathbf{X}$ & & \\
\hline
\end{tabular}

Fonte: elaborado pelo autor. 


\section{METODOLOGIA}

Neste trabalho foram realizadas pesquisa bibliográfica e análise de documentos. Para a pesquisa bibliográfica foram selecionadas revistas científicas com temas ligados ao agronegócio: Agroanalysis,Revista Brasileira de Gestão de Negócios, Organizações Rurais e Agroindustriais. Para a análise documental foram selecionados dados entre 2000 e 2020 dos principais jornais do Brasil relacionados ao campo econômico: Folha de São Paulo, Estado de São Paulo e Valor Econômico.

A coleta de dados foi realizada por meio do uso de palavras chaves definida após uma intensa pesquisa bibliográfica sobre certificação na cafeicultura e associações de estudos realizados no Brasil. Em seguida, as palavras chaves foram validadas por um especialista em pesquisas sobre o sistema agroindustrial do café.

O Quadro 3 apresenta a lista de palavras chave da pesquisa.

Quadro 3 - Lista de Palavras Chave Usadas na Pesquisa

\begin{tabular}{|l|l|}
\hline \multicolumn{1}{|c|}{ Palavra chave } & \multicolumn{1}{c|}{ Motivo de escolha } \\
\hline ABIC & Tema de Pesquisa \\
\hline Selo ABIC + Café & Tema de Pesquisa e Setor de pesquisa \\
\hline ABIC + associação & Tema de Pesquisa \\
\hline
\end{tabular}

Fonte: elaborado pelo autor.

Foram consultados artigos dos três principais jornais desde o ano 2000. Com base neste conjunto de documentos, foram selecionadas algumas notícias para citação com intuito de construir o cenário dos selos de qualidade da ABIC no mercado de cafés no Brasil. O Quadro 4 apresenta a lista de notícias selecionadas para a pesquisa. O Quadro 5 - lista artigos científicos selecionados para a pesquisa

O Quadro 4 - Lista de Notícias Selecionadas para a Pesquisa

\begin{tabular}{|l|l|c|}
\hline & \multicolumn{1}{|c|}{ Título/Jornal } & Data \\
\hline A1 & O Vaivém das commodities, Folha de São Paulo & $22 / 11 / 05$ \\
\hline A2 & País quer marketing no exterior para vender mais café, Estado de São Paulo & $24 / 05 / 10$ \\
\hline A3 & Café torrado passará a ter controle oficial, Estado de São Paulo & $24 / 11 / 10$ \\
\hline A4 & Quer um café campeão? Estado de São Paulo & $19 / 01 / 12$ \\
\hline A5 & Consumo de café no Brasil cresce 3,11\% em 10/11, Estado de São Paulo & $24 / 01 / 12$ \\
\hline A6 & $\begin{array}{l}\text { Empreendedores investem no café gourmet para atrair o consumidor mais } \\
\text { exigente, Estado de São Paulo }\end{array}$ & $03 / 09 / 13$ \\
\hline A7 & Doze xícaras de café direto do supermercado, Estado de São Paulo & $28 / 01 / 15$ \\
\hline A8 & Grupo Utam lança novos cafés da linha grãos especiais, Estado de São Paulo & $16 / 03 / 17$ \\
\hline A9 & Café gourmet ou especial? Folha de São Paulo & $25 / 01 / 18$ \\
\hline A10 & Uma safra de café que ficará na memória, Valor Econômico & $21 / 08 / 18$ \\
\hline A11 & Dia Nacional do Café: confira 10 curiosidades sobre a bebida, Estado de São Paulo & $24 / 05 / 20$ \\
\hline A12 & Fake news do café, Estado de São Paulo & $18 / 02 / 20$ \\
\hline A13 & $\begin{array}{l}\text { Como funciona a coleta e reciclagem de cápsulas de café na Nespresso, Estado de } \\
\text { São Paulo }\end{array}$ & $21 / 06 / 18$ \\
\hline
\end{tabular}

Fonte: elaborador pelo autor.

O Quadro 5 - Lista Artigos Científicos Selecionados para a Pesquisa

\begin{tabular}{|l|l|c|}
\hline \multicolumn{1}{|c|}{ Título/Jornal } & Data \\
\hline B1 & Frases e comentários, Agroanalysis, v. 34, n. 09 & $09 / 2014$ \\
\hline B2 & Especial Café, Agroanalysis, v. 33, n. 12 & $12 / 2013$ \\
\hline B3 & Especial Café, Agroanalysis, v. 30, n. 9 & $09 / 2010$ \\
\hline B4 & Estratégia de diferenciação no mercado brasileiro de café. RBGN, v. 8 & 2006 \\
\hline B5 & $\begin{array}{l}\text { Os Pilares da Qualidade: o processo de implementação do Programa de } \\
\text { Qualidade do Café (PQC). Organizações Rurais e Agroindustriais. }\end{array}$ & 2010 \\
\hline
\end{tabular}

Fonte: elaborado pelo autor. 
Com base no Quadro “Categorias Analíticas” (Quadro 2), foram analisados os relatos do caso em estudo na seção a seguir por meio do uso da numeração (1 a 18) destacando em negrito.

\section{4 - RESULTADOS 4.1 - PROGRAMA DE AUTO INSPEÇÃO DA INDÚSTRIA DO CAFÉ}

A ABIC é uma associação que foi instituída no ano de 1973 no intuito de representar institucionalmente as indústrias de torrefação e moagem de café no Brasil. Essa associação de interesse privado tornou-se reconhecida no mercado de café como uma entidade de referência para os consumidores, principalmente por meio de uma série de programas de certificação que funcionam como mecanismos sinalizadores da qualidade por meio dos selos de qualidade ABIC.

A ABIC lançou o Programa de Auto Inspeção da Indústria do Café no ano de 1989, conhecido como Selo da Pureza. Este programa foi criado para reverter a queda do consumo interno, acabou estabelecendo um novo perfil de transação para o setor cafeeiro. O Quadro 6 apresenta a pesquisa sobre selo de pureza ABIC.

Quadro 6 - Pesquisa sobre Selo de Pureza

\begin{tabular}{|c|c|c|}
\hline $\begin{array}{l} \\
\text { జ్ } \\
\text { I }\end{array}$ & & Conteúdo \\
\hline \multirow{5}{*}{ 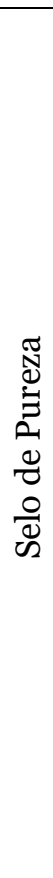 } & A12 & $\begin{array}{l}\text { A ABIC (Associação Brasileira da Indústria do Café) emitiu uma nota de } \\
\text { esclarecimento onde explica que nosso País tem critérios rigorosos quanto à pureza da } \\
\text { matéria prima empreqada nas torrefacões certificadas. (Estado de São Paulo) }\end{array}$ \\
\hline & B1 & $\begin{array}{l}\text { Os excelentes resultados obtidos com o Selo de Pureza e demais certificações são uma } \\
\text { demonstração clara de que exercer a autorregulamentação é uma realidade. Américo } \\
\text { Takamitsu Sato, presidente da Associação Brasileira da Indústria de Café (ABIC), } \\
\text { sobre os vinte e cinco anos de lançamento do Selo de Pureza ABIC, lembrando que, } \\
\text { para o varejo, as certificações são um atestado de segurança alimentar. (p. 12, } \\
\text { Agroanalvsis) og/2014 }\end{array}$ \\
\hline & B2 & $\begin{array}{l}\text { Copiados por diversos países produtores, a ABIC possui programas de certificação } \\
\text { únicos e importantes. Monitorando e certificando mais de } 1.300 \text { marcas no País, o } \\
\text { Programa de Autorregulamentação da Pureza do Café, com seu famoso Selo de Pureza, } \\
\text { por exemplo, assegura que o produto só contém grãos de café, ou seja, é puro. (p. } 28, \\
\text { Agroanalysis) } 12 / 2013\end{array}$ \\
\hline & B3 & $\begin{array}{l}\text { O campeão do mercado de café ainda é a tradicional bebida preparada no coador, o } \\
\text { famoso pingado de aroma irresistível e acompanhado de pão e manteiga na chapa na } \\
\text { padaria. NATHAN HERSZKOWICZ, da Associação Brasileira da Indústria de Café } \\
\text { (ABIC) (p. 12, Agroanalysis) } \\
09 / 2010\end{array}$ \\
\hline & B4 & $\begin{array}{l}\text { O Selo, muito mais que pureza, representava qualidade, o que imprimia um apelo } \\
\text { ainda maior para o seu uso, acabando por capitanear um número maior de empresas } \\
\text { ao Programa. (SAES, 2006, p. 27)- Revista Brasileira de Gestão de Negócios - } 2006\end{array}$ \\
\hline
\end{tabular}

Fonte: dados da pesquisa.

Em síntese, pode-se afirmar que o selo de pureza transmite a percepção de qualidade expandindo a representação de pureza. 


\section{2 - Programa de Qualidade do Café (PQC)}

Em 2004, a ABIC lançou o Programa de Qualidade do Café (PQC) visando reorientar o setor e mudar a percepção dos consumidores por meio da diferenciação.

O Quadro 7 apresenta documentos do selo PQC da ABIC. Após a implantação do selo PQC, constata-se pela análise que ele iniciou como sendo a proposta de um novo padrão alimentar no mercado de cafés brasileiro (2005-2010). A análise do período de 011-2014 demonstra o iniciou de maturação do processo de diferenciação no mercado interno, onde os consumidores por meio da compra de cafés com a certificação PQC começam valorar o café superior e o café gourmet. No período de 2015-2020, há a consolidação da diferenciação no mercado interno. 
Quadro 7: Pesquisa sobre o Selo PQC da ABIC

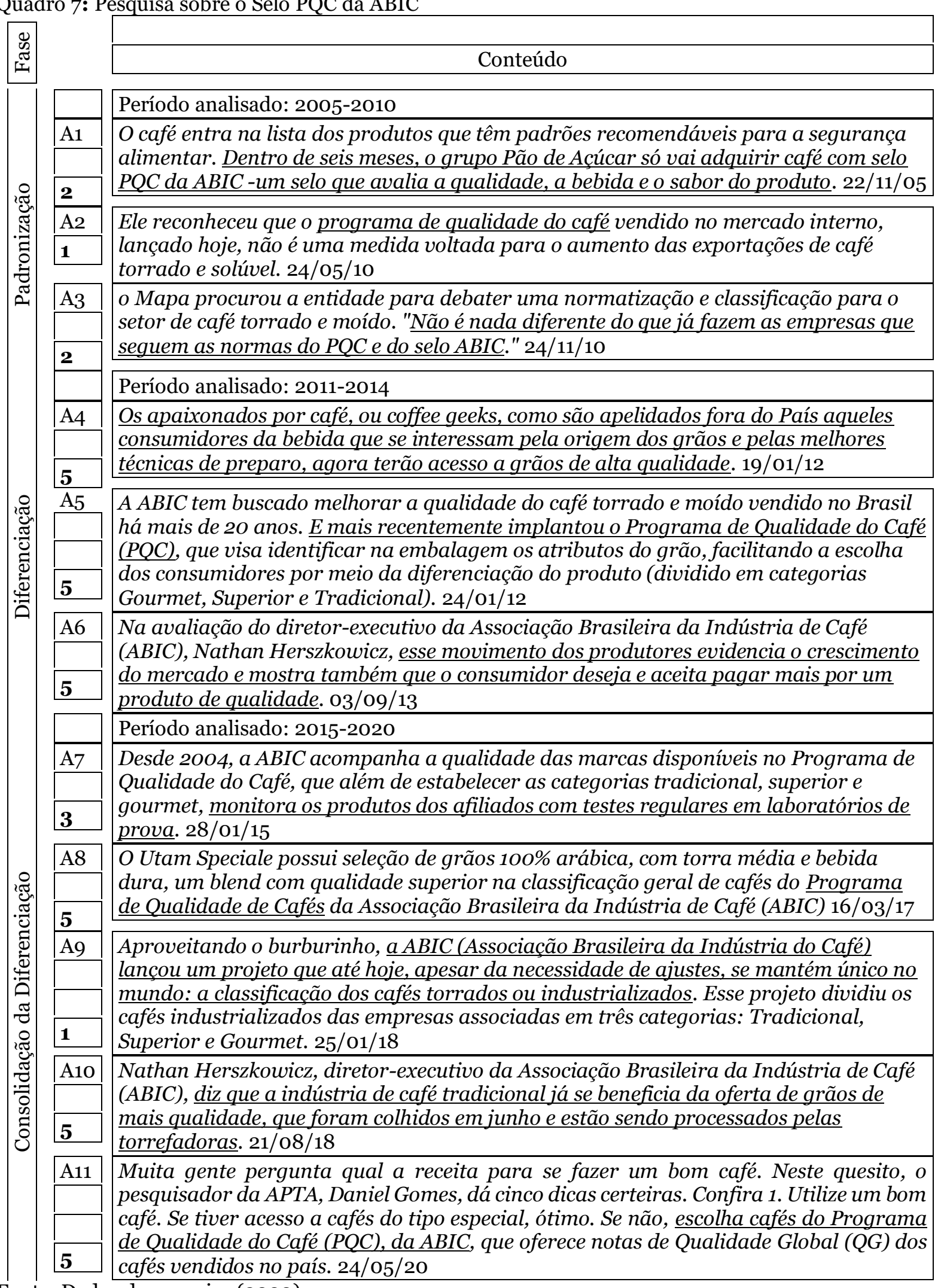

Fonte: Dados da pesquisa (2020).

A análise dos textos selecionados demonstra a aprovação da certificação PQC pelos consumidores de cafés diferenciados, destacando o consumo de cafés superior e gourmet. 
O Quadro 8 apresenta o detalhamento do processo do PQC da ABIC. Os cafés são coletados no ponto de venda, descaracterizado e enviados para Laboratórios Credenciados que irão executar os testes definidos no Quadro 8.

Quadro 8 - Processo do PQC da ABIC

\begin{tabular}{|c|c|c|c|}
\hline 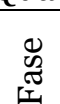 & 1. Análise da Bebida & $\begin{array}{l}\text { 2.Consistência de } \\
\text { Certificação }\end{array}$ & $\begin{array}{l}\text { 3.Análise de } \\
\text { Pureza }\end{array}$ \\
\hline 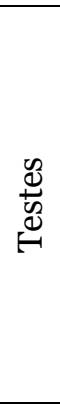 & $\begin{array}{l}\text { Qualidade Global (QG): Um grupo treinado } \\
\text { de provadores, de laboratórios credenciados } \\
\text { fará a análise sensorial do café seguindo } \\
\text { metodologia validada pela ABIC e verificará } \\
\text { a Qualidade Global da bebida. O que irá } \\
\text { determinar a Categoria de Qualidade do Café } \\
\text { será a faixa de nota final obtida pelo produto, } \\
\text { numa escala de o a 1O. A faixa da nota de } \\
\text { qualidade é obtida através do conjunto do } \\
\text { tipo de bebida, torra, etc. }\end{array}$ & $\begin{array}{l}\text { Coerência com a Ficha } \\
\text { Técnica: Os provadores } \\
\text { verificarão se as } \\
\text { características do café } \\
\text { estão de acordo com a } \\
\text { certificação e com as } \\
\text { características } \\
\text { declaradas pela } \\
\text { empresa. }\end{array}$ & $\begin{array}{l}\text { Microscopia: As } \\
\text { análises serão } \\
\text { realizadas em } \\
\text { laboratórios } \\
\text { credenciados pela } \\
\text { ABIC segundo } \\
\text { metodologia } \\
\text { oficial. }\end{array}$ \\
\hline 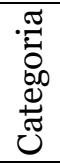 & $\begin{array}{l}\text { Cafés Tradicionais e/ou Extra Forte = nota } \\
\text { de } Q G>=4,5 \text { e }<5,9 \text { Cafés Superiores = nota } \\
\text { de } Q G>=6,0 \text { e }<7,2 \text { Cafés Gourmets = nota } \\
\text { de } Q G>=7,3 \text { até } 1 O\end{array}$ & & \\
\hline
\end{tabular}

Fonte: Baseado em dados da ABIC (2020).

Em estudo sobre o PQC de Leme e Machado (2010), foi demonstrado um aumento da coordenação vertical entre as empresas pesquisadas, envolvendo seus fornecedores e compradores, onde a rastreabilidade torna-se uma vantagem competitiva para os adotantes do PQC. Foi evidenciado que os torrefadores que trabalham com diferenciação necessitam do suporte de um selo de certificação ou de uma marca forte para transmitir credibilidade aos seus consumidores.

Em síntese, constata-se que o PQC conseguiu consolidar a diferenciação por meio da segmentação da qualidade dos cafés torrados.

\section{3 - Programa Cafés Sustentáveis do Brasil}

A expansão do mercado de cafés certificados nos mercados causou impactos no mercado de café no Brasil. Com essas mudanças, passa-se a exigir das associações atividades de coordenação não só em nível horizontal, mas também, em nível vertical. Dentro das novas atribuições que essas entidades podem realizar, evidencia-se que a certificação de firmas e coordenação da cadeia produtiva são atividades fundamentais para se gerar competitividade para as empresas e para o setor como um todo (BARRA e LADEIRA, 2016).

Neste contexto, a ABIC lançou o Programa Cafés Sustentáveis do Brasil (PCSB) em 2007 com o objetivo de introduzir o mercado brasileiro dentro da tendência mundial do consumo sustentável. O PCSB certifica café com rastreabilidade assegurada desde a produção até a industrialização (ABIC, 2020).

No PCSB, os produtos são produzidos com os cafés provenientes de fazendas certificadas quanto à sua produção sustentável. No PCSB, o processo de industrialização é auditado em relação as boas práticas de fabricação e os produtos classificados em categorias de qualidade por meio de uma metodologia de análise sensorial (ABIC, 2020).

Por fim, o selo de sustentabilidade permite café com diferenciação rastreados e certificados quanto à sustentabilidade. Pode-se afirmar que o selo de sustentabilidade ainda está em fase de consolidação. 


\section{3 - PROGRAMA DE CERTIFICAÇÃo DE CÁPSULAS}

Em 2016, a ABIC lançou o programa de certificação com metodologia orientada para a avaliação do café em cápsula. O Programa de Certificação de Cápsula (PCS) atesta a intensidade do café que é o grau de persistência do retrogosto, utilizando uma metodologia de avaliação sensorial desenvolvida pela ABIC, numa escala de compreendida entre o e 10, variando do mais suave até ao mais forte. O PCS oferece ao empresário uma avaliação global do seu produto, como as características da crema, os atributos da bebida, características físicas, entre outros (ABIC, 2020).

Em 2020, há 24 marcas de torrefadoras que obtiveram o Selo de Certificação ABIC para Café em Cápsula, apresentando a seguinte classificação: 13Gourmt, 5-Superior, 5-Tradicional e 1-Extraforte.

A metodologia para avaliação das características da bebida de café em cápsulas da ABIC foi elaborada em um projeto conjunto do Grupo de Avaliação do Café, do Instituto de Tecnologia de Alimentos (ITAL) e do Laboratório Carvalhaes, que são laboratórios credenciados para análise de café pela ABIC. A análise dos cafés em cápsulas é baseada no uso da análise sensorial para o café definida pelo PQC da ABIC (ABIC, 2020).

ABIC.

O Quadro 9 apresenta a pesquisa sobre o programa cafés em cápsulas da

Quadro 9 - Pesquisa sobre o Programa Cafés em Cápsulas da ABIC

\begin{tabular}{|c|c|c|}
\hline & & Conteúdo \\
\hline 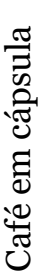 & $\mathrm{A} 13$ & $\begin{array}{l}\text { Um tipo de consumo específico de café vem crescendo nacionalmente. A possibilidade de } \\
\text { apreciar diferentes tons e sabores em doses menores cativou o brasileiro: o consumo de } \\
\text { café em cápsulas, segundo a ABIC, ainda deve aumentar mais de 100\% até } 2019 . \\
21 / 06 / 18\end{array}$ \\
\hline
\end{tabular}

Fonte: dados da pesquisa.

Por fim, o selo de certificação de cápsulas possibilita a diferenciação com apresentação da intensidade da bebida. Pode-se afirmar que o selo de certificação de cápsulas ainda está em fase de consolidação.

\section{5- DISCUSSÃO}

Pela análise das categorias definidas com base na revisão de literatura em relação aos trechos coletados de jornais sobre a atuação da ABIC, verificou-se que esta associação apresenta características de uma Agente de Coordenação.

A ABIC contribui para a coordenação do sistema agroindustrial do café ratificando estudos anteriores baseados na teoria institucional.

A análise do Quadro 10 demonstra que os cafés certificados do tipo Gourmet, Superior e Tradicional apresentam o maior percentual de cafés dentro dos programas de qualidade de café da ABIC. 
Quadro 10 - Marcas Certificadas - ABIC

\begin{tabular}{|l|c|c|c|c|c|c|c|c|c|}
\cline { 3 - 12 } \multicolumn{1}{c|}{} & \multicolumn{7}{c|}{ Quantidade } \\
\hline Certificação & & Gourmet & \multicolumn{2}{c|}{ Superior } & \multicolumn{2}{c|}{ Tradicional } & \multicolumn{2}{c|}{ Extraforte } \\
\hline & & & $\%$ & & $\%$ & & $\%$ & & $\%$ \\
\hline PQC & 754 & 215 & 28,51 & 157 & 20,82 & 268 & 35,54 & 114 & 15,12 \\
\hline Sustentabilidade & 24 & 13 & 54,17 & 10 & 41,67 & 1 & 4,17 & & \\
\hline Cápsulas & 24 & 13 & 54,17 & 5 & 20,83 & 5 & 20,83 & 1 & 4,17 \\
\hline Pureza & 1176 & - & & - & & - & & - & \\
\hline
\end{tabular}

Fonte: elaborado pelo autor.

O Quadro 11 apresenta análise comparativa dos selos ABIC. O selo de pureza foi criado para evitar impurezas no café. Mas, com o passar do tempo passou a traduzir qualidade, influenciando no aumento do número de empresas ao programa. O selo PQC além de representar qualidade, consolidou a diferenciação por meio da segmentação dos cafés. O selo de sustentabilidade permite café com diferenciação rastreados e certificados quanto à sustentabilidade. O selo de café em cápsulas possibilita a diferenciação com apresentação da intensidade da bebida.

Quadro 11 - Análise comparativa dos selos ABIC

\begin{tabular}{|c|c|c|c|c|}
\hline Certificado & $\mathrm{PQC}$ & Sustentabilidade & Cápsulas & Pureza \\
\hline Selo & 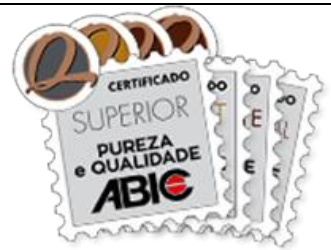 & 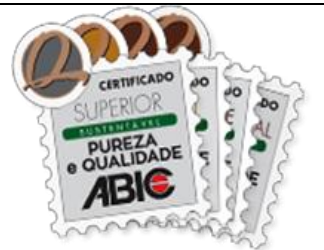 & $\left\{\begin{array}{c}\text { CERTIFICADO } \\
\text { ABIC } \\
\text { ANTENIDADE: } 05\end{array}\right\}$ & $\begin{array}{l}\text { SELO DE } \\
\text { PUREZA } \\
\text { AB|C }\end{array}$ \\
\hline Categorias & $\begin{array}{l}\text { Tradicional, } \\
\text { extraforte, } \\
\text { superior, } \\
\text { gourmet }\end{array}$ & $\begin{array}{l}\text { Tradicional, } \\
\text { extraforte, } \\
\text { superior, } \\
\text { gourmet }\end{array}$ & $\begin{array}{l}\text { Gourmet, } \\
\text { Superior, } \\
\text { Tradicional }\end{array}$ & \\
\hline Ênfase & Qualidade & $\begin{array}{l}\text { Qualidade com } \\
\text { Sustentabilidade }\end{array}$ & $\begin{array}{l}\text { Qualidade } \\
\text { Intensidade da } \\
\text { bebida }\end{array}$ & Pureza \\
\hline Metodologia & Avaliação sensorial & Avaliação sensorial & $\begin{array}{l}\text { Avaliação } \\
\text { sensorial }\end{array}$ & $\begin{array}{ll}\text { Avaliação } & \text { de } \\
\text { impurezas } & \\
\end{array}$ \\
\hline Escala & o a 10 & o a 10 & o a 10 & \\
\hline $\begin{array}{l}\text { Faixa da } \\
\text { Escala }\end{array}$ & $\begin{array}{l}\text { Tradicional, } \\
\text { extraforte, superior, } \\
\text { gourmet }\end{array}$ & $\begin{array}{l}\text { Tradicional, } \\
\text { extraforte superior, } \\
\text { gourmet }\end{array}$ & $\begin{array}{l}\text { De Suave ao mais } \\
\text { forte }\end{array}$ & \\
\hline $\begin{array}{l}\text { Audita o } \\
\text { Processo }\end{array}$ & $\begin{array}{l}\text { Boas práticas de } \\
\text { fabricação }\end{array}$ & $\begin{array}{l}\text { Boas práticas de } \\
\text { fabricação }\end{array}$ & $\begin{array}{l}\text { Boas práticas de } \\
\text { fabricação }\end{array}$ & $\begin{array}{l}\text { Verificação das } \\
\text { condições } \\
\text { técnicas de } \\
\text { fabricação }\end{array}$ \\
\hline Ponto Forte & Café diferenciação. & $\begin{array}{lr}\text { Café } & \text { com } \\
\text { diferenciação } & \\
\text { rastreados } & \mathrm{e} \\
\text { certificados quanto } & \\
\text { à sustentabilidade }\end{array}$ & $\begin{array}{lr}\text { Café } & \text { com } \\
\text { diferenciação } & \text { com } \\
\text { apresentação } & \text { da } \\
\text { intensidade } & \text { da } \\
\text { bebida } & \end{array}$ & $\begin{array}{lr}\text { Evita cafés } \\
\text { com alto } \\
\text { percentual de } \\
\text { impurezas }\end{array}$ \\
\hline
\end{tabular}

Fonte: dados da pesquisa. 
A partir da evolução histórica da implementação dos selos de qualidade da ABIC, pode-se afirmar que houve uma evolução partindo do conceito de pureza, que evoluiu para qualidade com diferenciação. Posteriormente, buscou-se aliar a diferenciação pela qualidade com a sustentabilidade e houve uma adequação a uma tendência do mercado, possibilitando diferenciação com apresentação da intensidade da bebida. Entende-se que o suporte da ABIC foi importante nos negócios de seus membros por meio de ações de coordenação.

Por fim, há que ressaltar que os selos providos pela ABIC podem reduzir o efeito free rider no mercado de café pelo fator de ser um tipo de instrumento sinalizador de qualidade. Os selos ABIC são instrumentos de coordenação de sistemas agroindustriais que garantem que o café tenha os atributos desejados pelo consumidor.

\section{CONSIDERAÇÕES FINAIS}

A ABIC tem atuado na mudança de imagem no mercado de cafés no que se refere à qualidade do café brasileiro. A partir da evolução das atividades da ABIC, pode-se afirmar que o suporte institucional de uma associação pode exercer um papel importante no suporte aos negócios por meio de ações de coordenação.

Neste artigo, foi analisado tanto a influência das ações ABIC nos negócios dos seus associados quanto as externalidades geradas por ela a toda cadeia produtiva do café no Brasil. Como contribuição teórica, propõe-se um esquema conceitual de análise para compreender o papel de associações em sistemas agroindustriais.

O suporte provido pela ABIC na coordenação do sistema agroindustrial dos cafés tem sido um fator importante para proporcionar força competitiva aos seus associados, bem como para todo o setor, em virtude das externalidades positivas criadas pelos seus selos de qualidade.

O selo de Pureza e o selo PQC já estão consolidados e amplamente reconhecidos no setor. $\mathrm{O}$ selo de pureza transmite a percepção de qualidade expandindo o conceito de pureza. Já o PQC além de representar qualidade, consolidou a diferenciação por meio da segmentação dos cafés. Os selos de sustentabilidade e de cápsulas estão em fase de consolidação.

A ABIC por meio de seus selos de qualidade contribui para a coordenação do sistema agroindustrial do café ratificando estudos anteriores baseados na teoria institucional.

A ABIC é uma evidência da expansão da atuação das associações nos sistemas agroindustriais. Todavia, acredita-se que estudos continuados de outras realidades do agronegócio brasileiro são necessários para a compreensão mais adequada dessa questão.

As associações que inicialmente eram voltadas à atuação como agentes de interface, isto é, como elos entre produtores e governo, transformaram-se, paulatinamente, em agentes que fomentam a confiança e a coordenação na agroindústria cafeeira.

Por fim, este trabalho apresenta-se certas limitações que estão relacionadas ao fato de ser um estudo exploratório, impedindo assim, generalizações. Dessa forma, sugere-se que estudos futuros de caráter longitudinal em outras associações do agronegócio café sejam realizados para aprofundamento deste tema. 


\section{REFERÊNCIAS}

ABIC - ASSOCIAÇÃO BRASILEIRA DA INDÚSTRIA DO CAFÉ. Disponível em: $<$ http.www.abic.com.br> Acesso em 16/07/2020. 2020.

BARRA, G. M. J.; OLIVEIRA, V. C. S.; MACHADO, R. T. M. O papel das associações de interesse privado no mercado cafeeiro brasileiro. Revista de Gestão da USP. São Paulo, São Paulo, v. 12, n. 3, p. 17-31, 2007.

BARRA, G. M. J.; LADEIRA, M. B. Teorias institucionais aplicadas aos estudos de sistemas agroindustriais no contexto do agronegócio café: uma análise conceitual. REGE. Revista de Gestão da USP. São Paulo, São Paulo, v. 23, n.2, p. 87-184, 2016.

DONER, R. F.; SCHNEIDER B. R. Business associations and economic development: Why some associations contribute more than others. Business and Politics, v. 2, n. 3, 2000, p. 261-288.

FARINA, E. M. M. Q.; AZEVEDO, P. F.; SAES, M. S. M. Competitividade: mercado, estado e organizações. São Paulo: Singular, 1997.

LEME, P. H. M. V.; MACHADO, R. T. M. Os pilares da qualidade: o processo de implementação do Programa de Qualidade do Café (PQC). Organizações Rurais e Agroindustriais, Lavras, v. 12, p. 234-248, 2010.

MACHADO FILHO, C. A. P.; MIZUMOTO, F. M.; ZYLBERSZTAJN, D. Governança e a lógica das associações de interesse privado: um estudo de caso da associação brasileira das indústrias de massas alimentícias. Caderno de Administração (UEM), São Paulo, v. 13, n 4, p. 15, 2006.

MACHADO FILHO, C. A. P. Ações coletivas: o papel das associações de interesse privado no agribusiness. In: I Seminário Brasileiro sobre a Nova Economia Institucional, 1., 1998, São Paulo. Anais... São Paulo: FEA/USP, 1998.

NASSAR, A. M. Eficiência das associações de interesse privado: uma análise do agronegocio brasileiro. Dissertação (Mestrado em Administração) Faculdade de Economia, Administração e Contabilidade. São Paulo. 2001.

NORTH, D. C. Instituciones, cambio institucional y desempeno económico. Mexico: Fondo de Cultura Econômica, 1993.

OLSON, M. A lógica da ação coletiva: os benefícios públicos e uma teoria dos grupos sociais. São Paulo: Edusp, 1999.

SAES, M. S. M.; FARINA, E. M. M. Q. ABIC: ações conjuntas e novos desafios frente à reestruturação do mercado. In: Seminário Internacional Pensa e Agribusiness, 8., 1998, São Paulo. Anais... São Paulo: FEA/USP, 1998.

SAES, M. S. M. A desregulamentação do mercado cafeeiro e as perspectivas para o mercado nacional. Revista de Economia e Sociologia, Brasília, v.33, n.3, p.7-34, 1995 . 
SAES, M. S. M. Organizações e instituições. In: ZYLBERSZTAJN, D.; NEVES, M.F. (Org.). Economia e gestão dos negócios agroalimentares: indústria de alimentos, indústria de insumos, produção agropecuária e distribuição. São Paulo: Pioneira. Cap.9, p.165-186. 2000.

SAES, M.S.M.; NAKAZONE, D. Estudo da competitividade de cadeias integradas no Brasil: impactos das zonas de livre comércio. Cadeia: café. São Paulo: FECAMP/ FIPE, 133p. 2002.

SAES, M. S. M.; SILVA, C. L.; E., F. H. Estratégia de diferenciação no mercado brasileiro de café. Revista Brasileira de Gestão de Negócios, São Paulo, v. 8, p. 24-31, 2006.

WILLIAMSON, O. E. The economic institutions of capitalism: firms, markets, relational contracting. New York: Free, 1985.

WILLIAMSON, O. E. The new institutional economics: taking stock, looking ahead Oliver E. Williamson. Journal of Economic Literature. v. 38, n. 3, p. 595-613, 2000.

Sobre o(s) Autor(es):

Geraldo Magela Jardim Barra

Professor da Universidade Federal de São João del-Rei (Departamento de Administração e Ciências Contábeis). Doutor em Administração pela Universidade Federal de Minas Gerais. Email: gmjbar@yahoo.com.br 